more quickly than men. As in the study of Kujala et $a l,{ }^{8}$ wounds were more common in male orienteers, which is probably caused by a more direct and aggressive running technique.

In both sexes there was a predominance of injuries during the first leg. It is possible that the physical strain of a mass start and the excitement at the beginning of the relay produced more injuries on the first leg than on other legs. Spiked shoes were not allowed in the first leg in these relay competitions and this eliminated the injuries caused by spikes, but on the other hand it might have resulted in more injuries caused by slippery terrain. In the men's relay, the darkness during the first three legs may also have contributed to a greater incidence of injuries. Although the last legs in both relays were longest, the fewest injuries occurred, which could be explained by the orienteers being spread over a broader time scale when starting this leg.

A consideration of the difference in injuries incurred by women and men and in different stages of the relay may have some importance in the prevention of injuries but this needs more investigation.

Ankle sprain is a typical injury in orienteering. ${ }^{3569}$ In our study, $25 \%$ of injuries were ankle sprains and there was a predominance of ankle sprains in the first leg. Ankle injuries were also the most usual injury that led to discontinuation of the race. Much attention should be given to the prevention of ankle injuries in orienteering, including prophylactic ankle disk training and the use of prophylactic ankle taping or ankle stabilisers. ${ }^{10-12}$

The authors thank Dr Tapani Alkula, Department of Sociology, Helsinki University, for his valuable comments.

1 Folan JM. Orienteering injuries. $\mathrm{Br} \quad \mathrm{f}$ Sports $\mathrm{Med}$ 1982;16:236-40.

2 Korpi J, Haapanen A, Svahn T. Frequency, location, and types of orienteering injuries. Scandinavian fournal of Sport Science 1987;9:53-6.

3 McLean I. First aid for orienteering in Scotland. Scientific fournal of Orienteering 1990;6:55-63.

4 Hintermann B, Hintermann M. Injuries in orienteering. A study of the Swiss 6-days orienteering event. Scientific fournal of Orienteering 1992;8:72-8.

5 Ekstrand J, Roos $H$, Tropp $H$. The incidence of ankle sprains in orienteering. Scientific fournal of Orienteering 1990;6:3-9.

6 Hintermann B, Hintermann M. Ankle sprains in orienteering: a simple injury? Scientific fournal of Orienteerorienteering: a simpl

7 Johansson C. Injuries in elite orienteers. Am 7 Sports Med 1986;14:410-15.

1986,14:410-15. Kujala UM, Nylund T, Taimela S. Acute
orienteering. Int $\mathcal{f}$ Sports Med 1995;16:122-5.

9 Linde $\mathrm{F}$. Injuries in orienteering. $\mathrm{Br} f \mathrm{f}$ Sports Med 1986;20:125-7.

10 Tropp H, Askling C, Gillquist J. Prevention of ankle sprains Am $\mathcal{f}$ Sports Med 1985;13:259-62.

11 Rovere GD, Clarke TJ, Yates CS, Burely K. Retrospective comparison of taping and ankle stabilizers in preventin ankle injuries. $A m \mathcal{F}$ Sports Med 1988;16:228-33.

12 Gauffin H, Tropp H, Odenrick P. Effect of ankle disk training on postural control in patients with functional instability of the ankle joint. Int $\mathcal{F}$ Sports Med 1988;9:141-4.

\title{
Sports medicine in primary care
}

The New England Baptist Hospital sports medicine department organised their first annual course in sports medicine in primary care in 1997. It was a new initiative for them as they had few previous links with family doctors or physiotherapists in the community. The two day course began with continental breakfast at 730 am to gather the participants for the 8 am lecture. The course was designed to make an anatomical tour of all sports injuries of the upper and lower limb, and included back pain for good measure. Orthopaedic surgeons and physiotherapists alternated their presentations so that injury and rehabilitation were covered in tandem. The speakers rattled through the slides so fast that if your attention drifted for a moment you would wake up in a different joint. In mitigation, the hand outs were exceptional and as good as many textbooks.

In the afternoon sessions we were taken to the Bioskills laboratory-an exceptional facility that is a hybrid of an anatomy laboratory and an orthopaedic theatre. After signing a comprehensive medicolegal waiver concerning AIDS, hepatitis, and any other viral agents we dressed in full length waterproof theatre gowns, protective shoes, gloves, and goggles. Inside the laboratory we examined a cadaver, dissected to show the injuries about which we had learnt in the morning. Anatomy seemed much more interesting than it ever did in medical school! In the next room they had arranged cadaveric knees and shoulders to allow us to insert arthroscopes. We revised our surface anatomy, and could inject knees and shoulder joints and see the needle tips on the arthroscope. We closed the afternoon with practical revision of joint examination on human (live!) subjects.

It was a superb, if very concentrated course. The local GPs thought it was expensive at $\$ 425$ for two days and it would be prohibitively expensive to travel from the UK for such a short time, but it was an excellent course, which I would thoroughly recommend. The teaching facility itself is well worth a visit and is one of few similar facilities in the United States.

DOMHNALL MACAULEY 